\title{
Achieving anti-sintering of supported platinum nanoparticles using a thermal management strategy
}

\author{
Shuting Wang ${ }^{1}$, Zian $\mathrm{Li}^{2,4}$, Ming Yang ${ }^{3,4}$, Yuming $\mathrm{Li}^{1}$, Ranjia $\mathrm{Li}^{1}$, Changchun $\mathrm{Yu}^{1}$, Yajun Wang ${ }^{1}$, \\ Yao Jiang ${ }^{1}$, Tao $\mathrm{Li}^{3,4}$, Jin-Xun Liu ${ }^{5^{*}}$, Hang Zhang ${ }^{3,4^{*}}$, Zhen Zhao ${ }^{1}$, Chunming $\mathrm{Xu}^{1}$ and \\ Guiyuan Jiang ${ }^{1^{*}}$
}

\begin{abstract}
Sintering inhibition of a catalyst at high temperatures is a challenge during heterogeneous catalysis. In this paper, we report that hexagonal boron nitride (h-BN) is an optimal material for anti-sintering $\gamma$ - $\mathrm{Al}_{2} \mathrm{O}_{3}$-supported $\mathrm{Pt}$ nanoparticles (NPs) originating from the high thermal conductivity of h-BN. The high thermal conductivity of h-BN ensures maximal heat dissipation from Pt NPs to $\gamma-\mathrm{Al}_{2} \mathrm{O}_{3}$, thereby causing both Ostwald ripening and particle coalescence of Pt NPs to be decelerated at elevated temperatures. Inhibition of Pt NP sintering is also shown in the reducible $\mathrm{TiO}_{2}$-supported Pt NPs with the help of h-BN. The proposed anti-sintering strategy using thermal management is universal, providing new insight into the design of anti-sintering materials and structures for a wide range of applications in heterogeneous catalysis.
\end{abstract}

Keywords: anti-sintering, thermal management, molecular dynamics, hexagonal boron nitride

\section{INTRODUCTION}

Heterogeneous catalysis converts resources and raw materials into energy and valuable chemicals in an economically efficient manner. Transition metal (TM) particles are commonly used catalysts and are often prepared in small sizes to maximize the atomic utilization efficiency. Sintering is a natural phenomenon in heterogeneous catalysis at elevated temperatures, wherein nanoand micron-sized particles aggregate into larger particles because of reduced surface energy $[1,2]$. Numerous important industrial catalytic reactions, including the production of chemicals, pharmaceuticals, clean fuels, and exhaust treatments for automobiles and stationary power plants, undergo a large loss of catalytic reactivity due to the sintering of supported metal nanoparticles (NPs) [3]. To minimize sintering, the strengthening of metalsupport interactions has allowed various methods and technologies to be established [4-12]. For example, TM sintering can also be decelerated by the strong steric hindrance effect, such as by encapsulating metal particles into core-shell or yolk-shell structures [13-19], anchoring metal particles into pores of the large surface area of catalytic supports [20-22], controlling the uniformity of the metal NPs [23-25], and synthesizing multi-element alloys [26-28]. However, active sites are often covered and cannot participate in chemical reactions in such strategies, decreasing the catalytic performance of TM NPs. Understanding the sintering mechanism and developing efficient approaches to inhibit TM NP sintering are desirable, yet continue to pose a challenge.

In this paper, we report a new strategy to achieve metal $\mathrm{NP}$ sintering resistance using thermal management from the microscale to macroscale. Molecular dynamic (MD) simulations were first performed to study the sintering mechanisms of Pt NPs over a $\gamma-\mathrm{Al}_{2} \mathrm{O}_{3}$ support, twodimensional (2D) hexagonal boron nitride (h-BN), graphene, and hexagonal boron arsenide (h-BAs), which are materials with high conductivities. We identified $\mathrm{h}-\mathrm{BN}$ as an optimal material for Pt NP anti-sintering. Pt NP sintering was conducted at $800 \mathrm{~K}$ on a $\gamma-\mathrm{Al}_{2} \mathrm{O}_{3}$ support. The introduction of $\mathrm{h}-\mathrm{BN}$ into a $\mathrm{Pt} / \gamma-\mathrm{Al}_{2} \mathrm{O}_{3}$ catalyst can inhibit the sintering of the highly dispersed Pt NPs at temperatures up to $1000 \mathrm{~K}$ by effectively dissipating ex-

\footnotetext{
${ }^{1}$ State Key Laboratory of Heavy Oil Processing, China University of Petroleum, Beijing, Beijing 102249, China

${ }^{2}$ Beijing National Laboratory for Condensed Matter Physics and Institute of Physics, Chinese Academy of Sciences, Beijing 100190, China

${ }^{3}$ Institute of Engineering Thermophysics, Chinese Academy of Sciences, Beijing 100190, China

${ }^{4}$ University of Chinese Academy of Sciences, Beijing 100049, China

${ }^{5}$ Department of Chemical Physics, School of Chemistry and Materials Science, University of Science and Technology of China, Hefei 230026, China

* Corresponding authors (emails: jianggy@cup.edu.cn (Jiang G); zhanghang@iet.cn (Zhang H); jxliu86@ustc.edu.cn (Liu JX))
} 
cess heat. The inhibition of sintering can be extended to reducible $\mathrm{TiO}_{2}$-supported Pt NPs. Our work provides a new approach for anti-sintering TM NPs on a broad range of supports at elevated temperatures.

\section{EXPERIMENTAL AND THEORETICAL SECTION}

\section{MD simulations of particle migration and coalescence}

MD simulations were performed using large-scale atomic/molecular massively parallel simulation code to study Pt NP sintering using a particle migration and coalescence (PMC) mechanism. Nose-Hoover implementations of the thermostats were used to control the temperature. The relative sintered density was obtained using mass-conservation in Equation (S1). Further details about non-isothermal sintering behaviors of different models are discussed in the Supplementary information (Table S1).

\section{Phonon spectrum and phonon density of states}

Density functional theory (DFT) calculations were performed within the projector-augmented wave pseudopotential as implemented with the Vienna Ab-initio Simulation Package (VASP). The generalized gradient approximation was adopted. The plane-wave cutoff energies were set at $350 \mathrm{eV}$. The Monkhorst-Pack sampling in the first Brillouin zone was gamma-centered. A 15- $\AA$ vacuum layer was set perpendicular to the surface and the ionic positions were fully optimized until the difference in total electronic energies was $<10^{-5} \mathrm{eV}$.

After structural relaxation, the phonon spectrum and phonon density of states (Phonon DOS) were calculated using the finite displacement method [29]. Force constant calculations were performed using reduced $k$-point sampling meshes of $4 \times 4 \times 4,2 \times 2 \times 2$, and $6 \times 6 \times 1$ for the $\mathrm{Pt}, \gamma-\mathrm{Al}_{2} \mathrm{O}_{3}$, and h-BN, respectively. The phonon frequencies were sampled on an $8 \times 8 \times 8 q$-point mesh for $\mathrm{Pt}$ and $\gamma-\mathrm{Al}_{2} \mathrm{O}_{3}$ and on a $10 \times 10 \times 1 q$-point mesh for h$\mathrm{BN}$.

\section{Material preparation and characterization}

h-BN was introduced into the substrate by using a mechanical mixture. Pt NPs were chemically deposited onto the substrate by using wet impregnation. Further preparation details are provided in the Supplementary information. Fourier transform infrared spectroscopy (FTIR) and in situ FT-IR were both recorded using a Bruker VERTEX 70. X-ray diffraction (XRD) was performed using a Bruker D8 Advance. Nitrogen adsorption/deso- rption isotherms were performed using a Micromeritics ASAP 2460. Inductively coupled plasma optical emission spectrometry (ICP-OES) was tested using an Agilent ICPOES 730. Scanning electron microscopy (SEM) was performed using an FEI Quanta 200F. Energy-dispersive Xray in the transmission electron microscopy (EDX-TEM) and high-angle annular dark-field scanning TEM (HAADF-STEM) were taken using an FEI F20. Thermogravimetric (TG) analysis was performed using a TGA/DSC 3+. In situ TEM spectroscopy was recorded on a JEM-2100F (JEOL Inc.) and an in situ heating TEM holder (model 652, Gatan Inc.) was used to control the temperature. Samples were heated for $5 \mathrm{~min}$ at a rate of $20 \mathrm{~K} \mathrm{~min}^{-1}$ and temperature was recorded in $100 \mathrm{~K}$ increments. Thermal conductivity was tested using a NETZSCH 447. A VarioCAM HD research 880 was employed for infrared thermal imaging. Details about hydrogen-oxygen titration are shown in the Supplementary information (Fig. S1).

\section{RESULTS AND DISCUSSION}

The sintering of metal NPs may occur following two different mechanisms, namely, Ostwald ripening (OR) and PMC. OR causes large particles to grow at the expense of smaller particles due to the migration of single metal atoms on the support [30]. Metal NPs can migrate and coalesce to form larger particles in the PMC sintering process [31], which is a crucial method of achieving NP growth. In this paper, MD simulation was performed to study Pt NP sintering on $\gamma-\mathrm{Al}_{2} \mathrm{O}_{3}$ through a PMC sintering mechanism. $\gamma-\mathrm{Al}_{2} \mathrm{O}_{3}$ was selected based on the fact that it is widely used as the support in heterogeneous catalysis due to its versatile physical-chemical properties [32]. The PMC sintering evolution of Pt NPs on the $\gamma$ $\mathrm{Al}_{2} \mathrm{O}_{3}$ (010) surface was evaluated. We observed that $\mathrm{Pt}$ NPs merge easily on $\gamma-\mathrm{Al}_{2} \mathrm{O}_{3}(010)$ at $1000 \mathrm{~K}$ (Fig. 1a) and that $\mathrm{Pt}$ sintering accelerates as the temperature increases (Fig. S2).

In this paper, we focus on $2 \mathrm{D}$ materials, which have attracted considerable attention due to their extraordinary physical and chemical properties, such as high charge-carrier mobility, high thermal conductivity, high optical activity, and high mechanical strength [33-40]. 2D materials are widely and commonly used as supports to disperse single noble metal atoms and NPs [41-44]. However, it is still unknown whether and which 2D materials can act as effective supports to achieve antisintering of Pt NPs. Pt NP sintering behaviors present in the three types of $2 \mathrm{D}$ materials (i.e., $\mathrm{h}$ - $\mathrm{BN}$, graphene, and h-BAs) were systematically studied. 2D h-BN, graphene, 


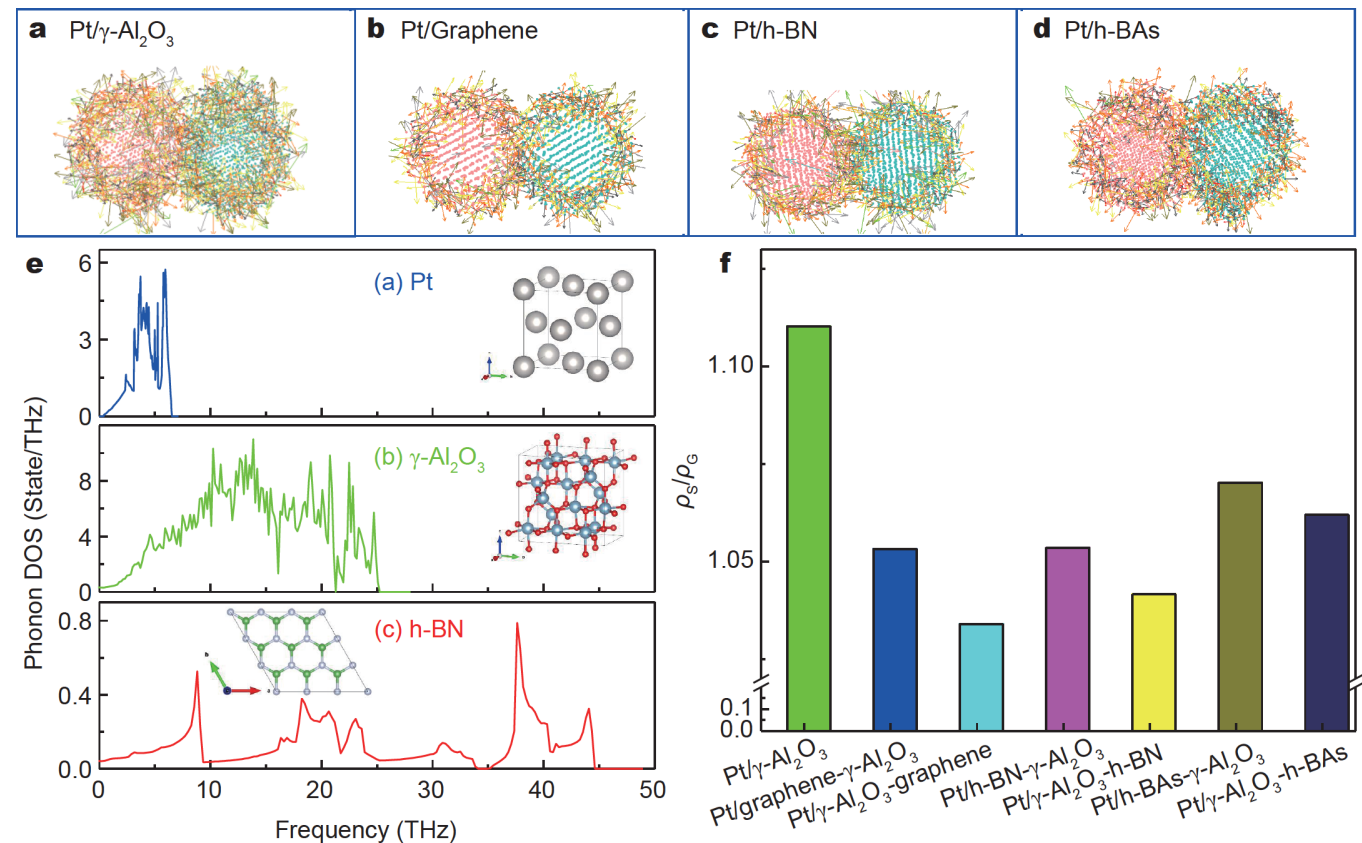

Figure 1 MD simulations and phonon DOS. Vector field distribution for NPs merging on (a) $\gamma-\mathrm{Al}_{2} \mathrm{O}_{3}$, (b) graphene, (c) h-BN, and (d) h-BAs supports predicted using MD simulations and following NP migration coalescence sintering mechanism. The 2D material supports are not shown to highlight Pt NP merging behaviors. (e) The phonon DOS of Pt, $\gamma-\mathrm{Al}_{2} \mathrm{O}_{3}$, and h-BN obtained using DFT calculation. (f) Relative sintered density of different model systems at the end of sintering process.

and h-BAs materials are selected here because they have higher thermal conductivities than $\gamma-\mathrm{Al}_{2} \mathrm{O}_{3}$ by one or two orders (Table S2).

New Pt-Pt bond formation is accompanied by heat release during Pt NP sintering due to PMC [45]. However, heat cannot dissipate effectively from $\gamma-\mathrm{Al}_{2} \mathrm{O}_{3}$, which has low thermal conductivity. Compared with $\mathrm{Pt} /$ $\gamma-\mathrm{Al}_{2} \mathrm{O}_{3}$, Pt NP sintering due to PMC decelerates on h$\mathrm{BAs}$, graphene, and $\mathrm{h}-\mathrm{BN}$ supports that have higher thermal conductivities than $\gamma-\mathrm{Al}_{2} \mathrm{O}_{3}$ (Fig. 1a-d). Heat released from Pt NP merging can facilitate fast heat dissipation on the 2D materials, preventing build-up of hot spots on Pt NPs. Pt/graphene displays the optimized performance for Pt NP anti-sintering, followed by h-BN and h-BAs (Fig. 1b-d), which can be attributed to the higher thermal conductivity of graphene than h-BN and h-BAs. Nevertheless, the structure collapse of graphene occurs at high temperatures and is likely to be removed during catalyst regeneration [46]. Therefore, we adopt h$\mathrm{BN}$ as an optimal choice in this anti-sintering study by also considering its strong chemical inertness, thermal conductivity, superior temperature stability, acid-base resistance, and low cost $[47,48]$.

An h-BN support can inhibit Pt NP sintering. However, the migration of Pt NPs occurs frequently on the highly crystalline surface of h-BN and few Pt NPs can anchor onto an h-BN surface due to the weak interactions between h-BN and Pt NPs. Synthesizing a low crystallized h-BN support to maintain the high dispersion of Pt NPs is a possible solution [49]. However, this will lower the thermal conductivity of the h-BN support that accelerates Pt NP sintering. We have thereby resorted to other approaches to decelerate the sintering of Pt NPs with a high dispersion. The $\gamma-\mathrm{Al}_{2} \mathrm{O}_{3}$ support binds Pt NPs more strongly in comparison with h-BN [50], and therefore, $\mathrm{Pt}$ NPs prefer to anchor onto the surface of $\gamma-\mathrm{Al}_{2} \mathrm{O}_{3}$ in the presence of both $\gamma-\mathrm{Al}_{2} \mathrm{O}_{3}$ and h-BN supports. This finding was corroborated by our STEM characterization (Fig. S3). Hence, we propose a new strategy to relieve sintering of $\mathrm{Pt} \mathrm{NPs}$ by combining $\gamma-\mathrm{Al}_{2} \mathrm{O}_{3}$ and $\mathrm{h}-\mathrm{BN}$ to produce a composite support. First, h-BN can prevent Pt NP sintering through the PMC mechanism. The heat released by Pt NPs that are growing and merging can dissipate quickly through h-BN with high thermal conductivity. Second, sintering via OR predicts that large metal-support interactions results in a high rate of sintering due to the large migration of atoms along the support. The weak interaction between single Pt atoms and h-BN [51] inhibits Pt NP sintering via the OR mechanism. Third, highly dispersed Pt NPs can be deposited on $\gamma-\mathrm{Al}_{2} \mathrm{O}_{3}$.

To prove our hypothesis, we resort to phonon DOS calculations. We found that the phonons of $\gamma-\mathrm{Al}_{2} \mathrm{O}_{3}$ are 
primarily distributed between $0-25 \mathrm{THz}$ (Fig. 1e). The phonon DOS of h-BN shows obvious peaks at $\sim 9,18$ and $38 \mathrm{THz}$. However, for Pt NPs, the overwhelming majority of phonons have frequencies $<7 \mathrm{THz}$ (Fig. 1e). This could be attributed to the heavier atomic mass and weaker inter-atomic force of the Pt NPs than the h-BN samples. In general, a stronger mismatch in the phonon DOS distributions will result in higher interfacial thermal resistance on the interface between materials [52], which will retard heat dissipation across the interfaces. Therefore, judging by the mismatch in phonon DOS distributions among $\mathrm{Pt}, \gamma-\mathrm{Al}_{2} \mathrm{O}_{3}$, and h-BN, the $\mathrm{Pt} / \gamma-\mathrm{Al}_{2} \mathrm{O}_{3}-\mathrm{h}-\mathrm{BN}$ is an optimal configuration for decelerating Pt NP sintering. A schematic diagram of two different configurations is shown in Fig. S4.

To verify the design strategy, we adopted an MD approach to simulate the sintering procedure when three $2 \mathrm{D}$ materials with high thermal conductivity (h-BN, h-BAs, and graphene) were introduced into $\mathrm{Pt} / \gamma-\mathrm{Al}_{2} \mathrm{O}_{3}$ systems (Fig. 1e). The results show that the $\mathrm{Pt} / \gamma-\mathrm{Al}_{2} \mathrm{O}_{3}$ system has the highest relative sintered density, which indicates the least anti-sintering performance. Combined with a series of high thermal conductivity 2D composites, the relative sintered densities of Pt NPs decease in different grades (Fig. 1f). Moreover, among all the systems, the " $\mathrm{Pt} / \gamma$ $\mathrm{Al}_{2} \mathrm{O}_{3}$-2D-material" configurations demonstrate better anti-sintering performances than their counterparts. This confirmed that, as we proposed, $\mathrm{Pt} / \gamma-\mathrm{Al}_{2} \mathrm{O}_{3}-\mathrm{h}-\mathrm{BN}$ is an optimal material for decelerating Pt sintering. The phonon DOS distributions of h-BN, h-BAs [53], and graphene [54] demonstrate a stronger mismatch with Pt NPs than with $\gamma-\mathrm{Al}_{2} \mathrm{O}_{3}$ and this can be explained by the analysis of phonon DOS distributions previously discussed. Placing $\gamma-\mathrm{Al}_{2} \mathrm{O}_{3}$ between Pt NPs and the high thermal conductive components may be an optimal strategy.

To confirm our theoretical predictions, $\mathrm{Pt} / \gamma-\mathrm{Al}_{2} \mathrm{O}_{3}$ and $\mathrm{Pt} / \gamma-\mathrm{Al}_{2} \mathrm{O}_{3}-\mathrm{h}-\mathrm{BN}$ samples were successfully synthesized to understand their sintering behaviors. First, the surface properties, crystallinity, specific surface area, and textural structure of the four samples, $\gamma-\mathrm{Al}_{2} \mathrm{O}_{3}, \gamma-\mathrm{Al}_{2} \mathrm{O}_{3}-\mathrm{h}-\mathrm{BN}, \mathrm{Pt} /$ $\gamma-\mathrm{Al}_{2} \mathrm{O}_{3}$, and $\mathrm{Pt} / \gamma-\mathrm{Al}_{2} \mathrm{O}_{3}-\mathrm{h}-\mathrm{BN}$, were characterized using FT-IR, XRD, and $\mathrm{N}_{2}$ adsorption and desorption isotherm characterization techniques (Figs S5, S6). Two typical FTIR absorption bands at 1378 and $816 \mathrm{~cm}^{-1}$ are identified for the high-purity commercial h-BN [55]. XRD characterization confirmed the existence of a hexagonal crystal structure of boron nitride and alumina is present in the gamma phase. Both $\gamma-\mathrm{Al}_{2} \mathrm{O}_{3}$ and h-BN retain their original phases after the introduction of Pt NPs and during the heating process (Fig. S6).

$\mathrm{N}_{2}$-sorption isotherms were obtained to reveal the textural structure of $\mathrm{Pt} / \gamma-\mathrm{Al}_{2} \mathrm{O}_{3}$ and $\mathrm{Pt} / \gamma-\mathrm{Al}_{2} \mathrm{O}_{3}-\mathrm{h}-\mathrm{BN}$ samples calcined at different temperatures (Fig. S5b and Table S3). Compared with $\mathrm{Pt} / \gamma-\mathrm{Al}_{2} \mathrm{O}_{3}$, the Barrett-JoynerHalenda pore size of $\mathrm{Pt} / \gamma-\mathrm{Al}_{2} \mathrm{O}_{3}$-h-BN is slightly smaller (Fig. S5b inset), which can be explained by the low specific surface area of pristine commercial h-BN (Table S3). Sintering of $\gamma-\mathrm{Al}_{2} \mathrm{O}_{3}$ and $\gamma-\mathrm{Al}_{2} \mathrm{O}_{3}$-h-BN substrates is not observed by raising the temperature from 773 to $973 \mathrm{~K}$ due to the high Tammann temperature of alumina $(1500 \mathrm{~K})$ and high thermal stability of h-BN [56]. Therefore, a minor fluctuation of the Brunauer-EmmettTeller (BET) surface area of $\mathrm{Pt} / \gamma-\mathrm{Al}_{2} \mathrm{O}_{3}$ and $\mathrm{Pt} / \gamma-\mathrm{Al}_{2} \mathrm{O}_{3}$-h$\mathrm{BN}$ with variation in temperature exists even up to $973 \mathrm{~K}$.

The initial mass fraction and dispersion of Pt NPs in the $\mathrm{Pt} / \gamma-\mathrm{Al}_{2} \mathrm{O}_{3}$ and $\mathrm{Pt} / \gamma-\mathrm{Al}_{2} \mathrm{O}_{3}$-h-BN samples were measured using ICP-OES and hydrogen-oxygen titration, respectively (Table $\mathrm{S} 4$ ). A lower platinum dispersion was observed in $\mathrm{Pt} / \gamma-\mathrm{Al}_{2} \mathrm{O}_{3}-\mathrm{h}-\mathrm{BN}$ than in $\mathrm{Pt} / \gamma-\mathrm{Al}_{2} \mathrm{O}_{3}$, which corresponds to the inhibited sintering behavior of $\mathrm{Pt} / \gamma$ $\mathrm{Al}_{2} \mathrm{O}_{3}-\mathrm{h}-\mathrm{BN}$. The high temperature sintering process was examined for the $\mathrm{Pt} / \gamma-\mathrm{Al}_{2} \mathrm{O}_{3}$ and $\mathrm{Pt} / \gamma-\mathrm{Al}_{2} \mathrm{O}_{3}$-h-BN samples using in situ TEM (Fig. 2). Pt NPs initially have the same size distribution of $2.6 \pm 0.4 \mathrm{~nm}$ on both $\gamma-\mathrm{Al}_{2} \mathrm{O}_{3}$ and $\gamma-\mathrm{Al}_{2} \mathrm{O}_{3}$-h-BN supports. Pt NPs are predominantly deposited on the surface of the $\gamma-\mathrm{Al}_{2} \mathrm{O}_{3}$ support (length of alumina nanotube is $\sim 20 \mathrm{~nm}$ ) for the $\mathrm{Pt} / \gamma-\mathrm{Al}_{2} \mathrm{O}_{3}$, whereas for $\mathrm{Pt} / \gamma-\mathrm{Al}_{2} \mathrm{O}_{3}-\mathrm{h}-\mathrm{BN}, \mathrm{h}-\mathrm{BN}$ (width of $\mathrm{h}-\mathrm{BN}$ wafer is $\sim 13 \mu \mathrm{m}$ ) blends with $\gamma-\mathrm{Al}_{2} \mathrm{O}_{3}$ (Fig. S7). Using EDX in conjunction with TEM characterization, we found that $\mathrm{Pt}$ NPs are predominantly deposited on $\gamma-\mathrm{Al}_{2} \mathrm{O}_{3}$ in the $\mathrm{Pt} / \gamma$ $\mathrm{Al}_{2} \mathrm{O}_{3}$-h-BN sample (Fig. S3).

Sintering can occur at elevated temperatures, namely, $\mathrm{Pt}$ NPs supported on $\gamma-\mathrm{Al}_{2} \mathrm{O}_{3}$ grow larger with the increase of temperature from 300 to $1000 \mathrm{~K}$ (Fig. 2a-h). Pt NPs are supported on $\gamma-\mathrm{Al}_{2} \mathrm{O}_{3}$ sinter via both OR and PMC mechanisms. At $800 \mathrm{~K}$, Pt NPs on $\gamma-\mathrm{Al}_{2} \mathrm{O}_{3}$ begin to coalesce into a single particle as they meet in regime I. OR occurs when larger Pt NPs grow at the expense of smaller particles in regime II after increasing the temperature to $800 \mathrm{~K}$. For the $\mathrm{Pt} / \gamma-\mathrm{Al}_{2} \mathrm{O}_{3}-\mathrm{h}-\mathrm{BN}$ sample, no obvious aggregation of Pt NPs occurs below $800 \mathrm{~K}$ (Fig. 2i-p). Pt NP sintering becomes increasingly evident on $\mathrm{Pt} / \gamma-\mathrm{Al}_{2} \mathrm{O}_{3}-\mathrm{h}$ $\mathrm{BN}$ when the temperature increases to $>900 \mathrm{~K}$ due to PMC and OR. Pt NPs always have a smaller size when supported on $\gamma-\mathrm{Al}_{2} \mathrm{O}_{3}$-h-BN than when on $\gamma-\mathrm{Al}_{2} \mathrm{O}_{3}$ from 300 to $1000 \mathrm{~K}$ (Fig. 3a). The experimental findings are corroborated with our theoretical predictions that the addition of h-BN to $\gamma-\mathrm{Al}_{2} \mathrm{O}_{3}$ would hinder Pt NP sin- 


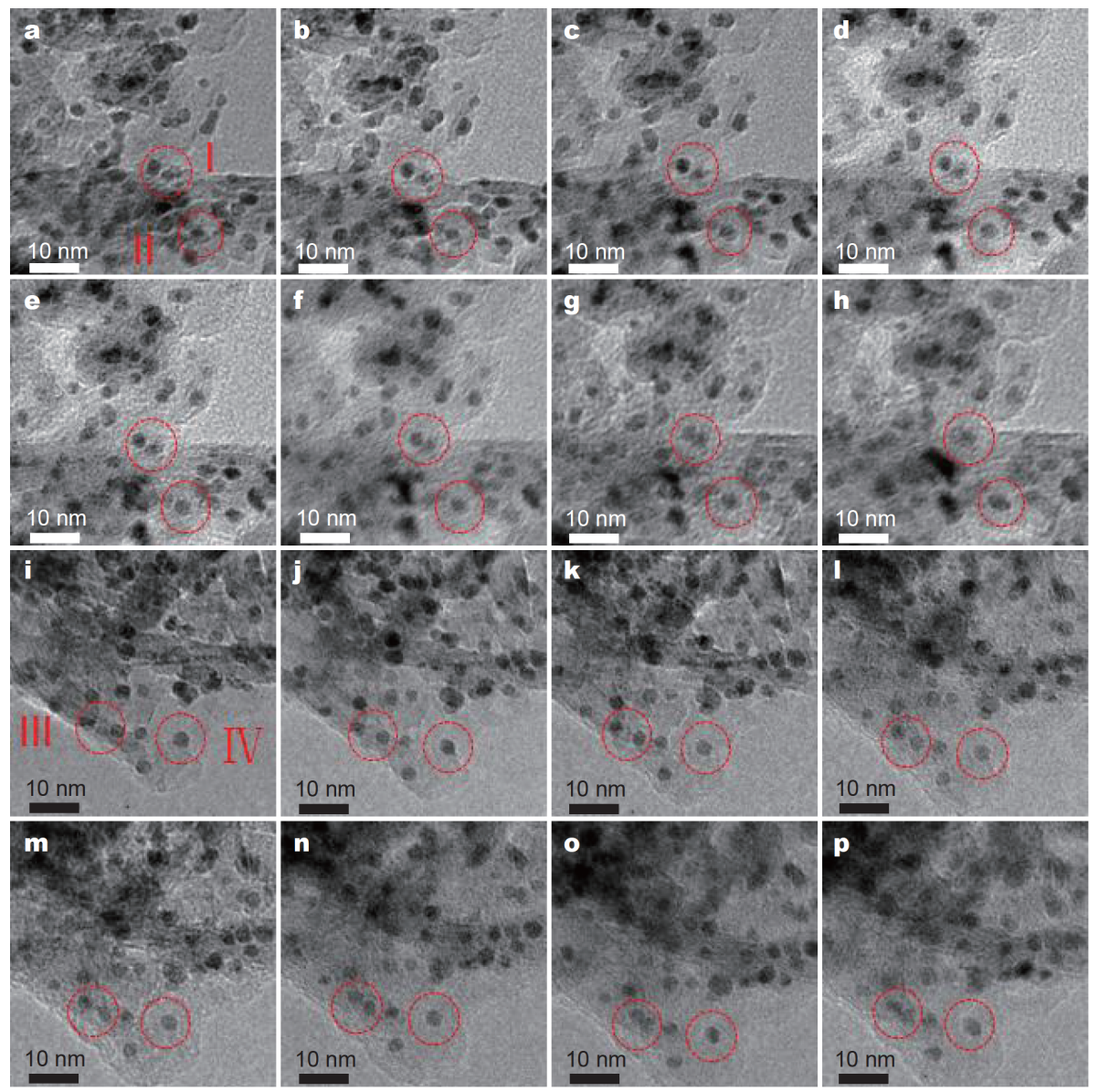

Figure 2 In situ TEM characterization of sintering of $\mathrm{Pt} / \gamma-\mathrm{Al}_{2} \mathrm{O}_{3}$ and $\mathrm{Pt} / \gamma-\mathrm{Al}_{2} \mathrm{O}_{3}-\mathrm{h}-\mathrm{BN}$. TEM images of $\mathrm{Pt} / \gamma-\mathrm{Al}_{2} \mathrm{O}_{3}$ at temperatures of (a) $300 \mathrm{~K}$, (b) $400 \mathrm{~K}$, (c) $500 \mathrm{~K}$, (d) $600 \mathrm{~K}$, (e) $700 \mathrm{~K}$, (f) $800 \mathrm{~K}$, (g) $900 \mathrm{~K}$, and (h) $1000 \mathrm{~K}$. TEM images of Pt $/ \mathrm{\gamma}^{-} \mathrm{Al}_{2} \mathrm{O}_{3}-\mathrm{h}-\mathrm{BN}$ at temperatures of (i) $300 \mathrm{~K}$, (j) $400 \mathrm{~K}$, (k) $500 \mathrm{~K}$, (l) $600 \mathrm{~K},(\mathrm{~m}) 700 \mathrm{~K}$, (n) $800 \mathrm{~K}$, (o) $900 \mathrm{~K}$, and (p) $1000 \mathrm{~K}$.

tering. The better anti-sintering ability of $\mathrm{Pt} / \mathrm{\gamma}-\mathrm{Al}_{2} \mathrm{O}_{3}-\mathrm{h}-$ $\mathrm{BN}$ can be attributed to two primary causes. When the $\mathrm{Pt}$ NPs were loaded on the $h-B N$ in the $\mathrm{Pt} / \gamma-\mathrm{Al}_{2} \mathrm{O}_{3}-\mathrm{h}-\mathrm{BN}$ sample, weak metal-support between single $\mathrm{Pt}$ atoms and h-BN inhibits OR sintering and high thermal conductivity of h-BN hinders sintering due to PMC. When the Pt NPs were loaded on the $\gamma-\mathrm{Al}_{2} \mathrm{O}_{3}$ in the $\mathrm{Pt} / \gamma-\mathrm{Al}_{2} \mathrm{O}_{3}-$ h-BN sample, Pt NP sintering due to OR and PMC mechanisms decelerates because of the high thermal conductivity of h-BN.

HAADF-STEM characterizations were further performed to identify Pt NP sintering during a long-term heating process with an elevated temperature rate of $1.58 \mathrm{~K} \mathrm{~min}^{-1}$ (Fig. 3a, b and Figs S8-S10). Pt NP sintering on $\gamma-\mathrm{Al}_{2} \mathrm{O}_{3}$ can be typically divided into three phases. In phase I at temperatures below $773 \mathrm{~K}$, Pt NPs on $\gamma-\mathrm{Al}_{2} \mathrm{O}_{3}$ are a relatively uniform size of $<5 \mathrm{~nm}$. The Pt NP sintering rate is slow at low temperatures in phase I. In phase
II, the temperature rises from 773 to $873 \mathrm{~K}$ and $\mathrm{OR}$ and $\mathrm{PMC}$ are responsible for the rapid $\mathrm{Pt} \mathrm{NP}$ growth. The particle size of Pt NPs supported on $\gamma-\mathrm{Al}_{2} \mathrm{O}_{3}$ grows from $11.3 \pm 4.1 \mathrm{~nm}$ to $13.5 \pm 3.4 \mathrm{~nm}$ during phase III when temperatures increase from 873 to $973 \mathrm{~K}$. However, the particle size of Pt NPs supported on $\gamma-\mathrm{Al}_{2} \mathrm{O}_{3}$-h-BN grows from $6.8 \pm 2.0 \mathrm{~nm}$ to $9.2 \pm 2.1 \mathrm{~nm}$ during phase III. Although $\mathrm{Pt} / \gamma-\mathrm{Al}_{2} \mathrm{O}_{3}$-h-BN has a similar sintering behavior as $\mathrm{Pt} / \gamma-\mathrm{Al}_{2} \mathrm{O}_{3}$ does, $\mathrm{Pt} \mathrm{NPs}$ have a lower growth rate on $\gamma$ $\mathrm{Al}_{2} \mathrm{O}_{3}$-h-BN than on $\gamma-\mathrm{Al}_{2} \mathrm{O}_{3}$ below $973 \mathrm{~K}$ (Fig. 3b).

Consistent with in situ TEM characterizations, sintering of Pt NPs is inhibited during the three phases by introducing $\mathrm{h}-\mathrm{BN}$ in $\mathrm{Pt} / \gamma-\mathrm{Al}_{2} \mathrm{O}_{3}$-h-BN through HAADFSTEM analysis (Fig. 3a, b). Because sintering is a thermodriven process, the Pt NPs supported on the substrate migrate from a place of high temperature to one of low temperature as driven by the temperature gradient [5759]. The thermal gradient driving force for grain 

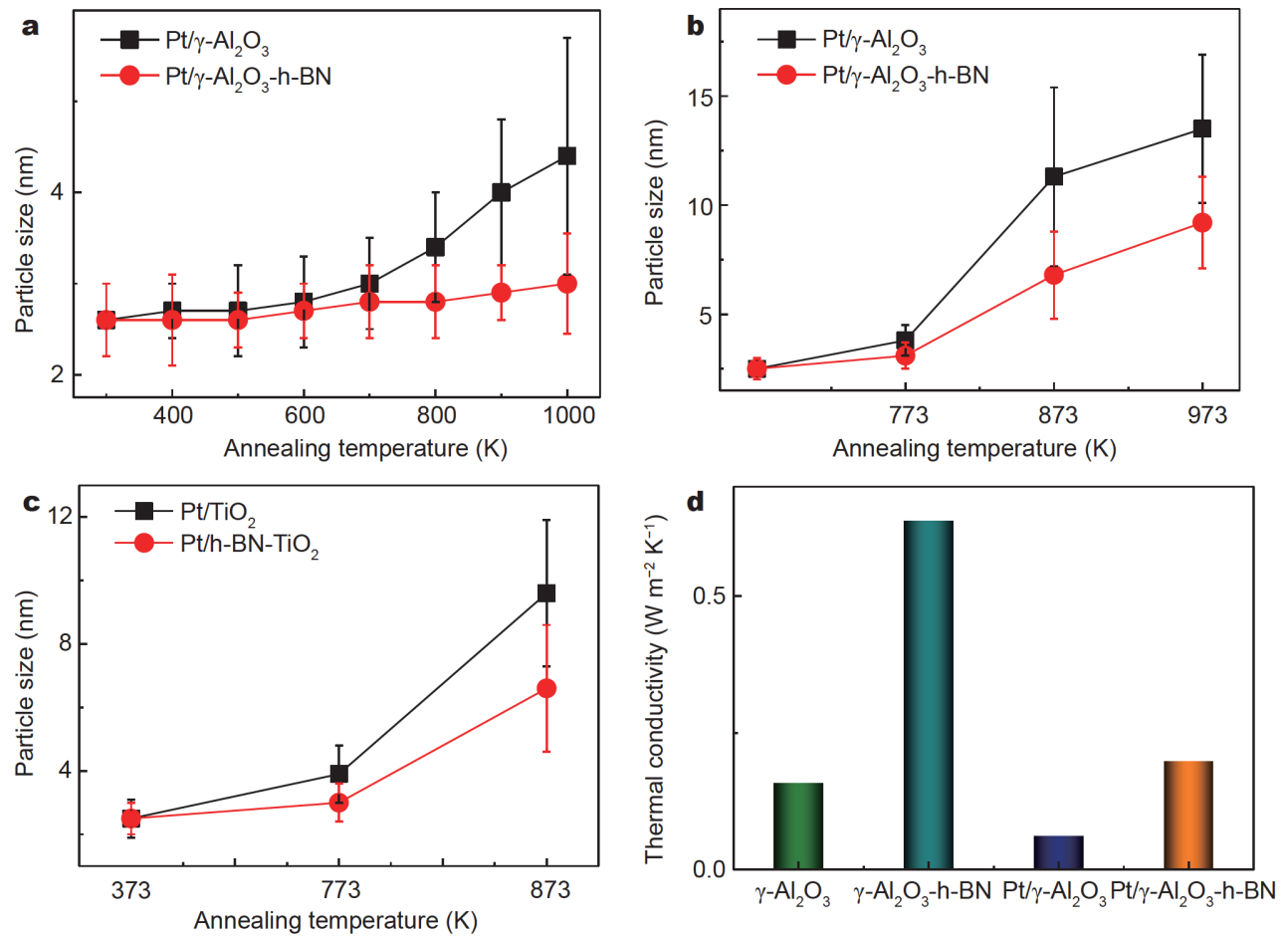

Figure 3 Particle-size distribution and thermal properties. (a) Particle-size distribution of $\mathrm{Pt} / \gamma-\mathrm{Al}_{2} \mathrm{O}_{3}$ and $\mathrm{Pt} / \gamma-\mathrm{Al}_{2} \mathrm{O}_{3}$-h- $\mathrm{BN}$ under in situ TEM. Particle-size distribution of (b) $\mathrm{Pt} / \gamma-\mathrm{Al}_{2} \mathrm{O}_{3}$ and $\mathrm{Pt} / \gamma-\mathrm{Al}_{2} \mathrm{O}_{3}$-h- $\mathrm{BN}$ and (c) $\mathrm{Pt} / \mathrm{TiO}_{2}$ and $\mathrm{Pt} / \mathrm{TiO}_{2}$-h- $\mathrm{BN}$ in aberration-corrected HAADF-STEM images. (d) Thermal conductivities of $\mathrm{Pt} / \gamma-\mathrm{Al}_{2} \mathrm{O}_{3}$ and $\mathrm{Pt} / \gamma-\mathrm{Al}_{2} \mathrm{O}_{3}-\mathrm{h}-\mathrm{BN}$ obtained using a laser flash apparatus.

boundary migration is proportional to the thermal gradient [57]. Infrared thermal imaging camera results show a more uniform temperature field distribution after introduction of h-BN in $\mathrm{Pt} / \gamma-\mathrm{Al}_{2} \mathrm{O}_{3}$ (Fig. $4 \mathrm{a}-\mathrm{d}$ ). A gentler temperature distribution trend for $\mathrm{Pt} / \gamma-\mathrm{Al}_{2} \mathrm{O}_{3}-\mathrm{h}-\mathrm{BN}$ than for $\mathrm{Pt} / \gamma-\mathrm{Al}_{2} \mathrm{O}_{3}$ is shown in Fig. $4 \mathrm{a}-\mathrm{d}$ and Fig. S11. The thermal gradient ratio of $\mathrm{Pt} / \gamma-\mathrm{Al}_{2} \mathrm{O}_{3}$ and $\mathrm{Pt} / \gamma-\mathrm{Al}_{2} \mathrm{O}_{3}-\mathrm{h}$ $\mathrm{BN}$ is 2, indicating that a stronger driving force exists for $\mathrm{Pt} N \mathrm{~N}$ sintering in $\mathrm{Pt} / \gamma-\mathrm{Al}_{2} \mathrm{O}_{3}$ than for $\mathrm{Pt} / \gamma-\mathrm{Al}_{2} \mathrm{O}_{3}-\mathrm{h}-\mathrm{BN}$. The thermal conductivity of $\mathrm{Pt} / \gamma-\mathrm{Al}_{2} \mathrm{O}_{3}-\mathrm{h}-\mathrm{BN}$ is four times that of $\mathrm{Pt} / \gamma-\mathrm{Al}_{2} \mathrm{O}_{3}$ (Fig. 3d). The high in-plane thermal conductivity of h-BN [60], which facilitates heat transformation, makes a large contribution to a lower thermal gradient in $\mathrm{Pt} / \gamma-\mathrm{Al}_{2} \mathrm{O}_{3}-\mathrm{h}-\mathrm{BN}$. As a result, the more uniform temperature field distribution decreases the thermal gradient-driven force for Pt NP sintering at a macroscale in $\mathrm{Pt} / \gamma-\mathrm{Al}_{2} \mathrm{O}_{3}-\mathrm{h}-\mathrm{BN}$. In other words, thermal interface resistance between Pt NPs and substrates is reduced and the excess heat for Pt NPs can be transported quickly with the help of h-BN-inhibited sintering of $\mathrm{Pt}$ NPs in $\mathrm{Pt} / \gamma-\mathrm{Al}_{2} \mathrm{O}_{3}-\mathrm{h}-\mathrm{BN}$.

In this paper, we proposed an efficient strategy to antisintering Pt NPs by introducing h-BN, a material with high thermal conductivity, into $\gamma-\mathrm{Al}_{2} \mathrm{O}_{3}$. Our strategy for anti-sintering metal NPs by means of thermal management is different from previous approaches, namely, by strengthening the metal-support interaction effect [4-12], which enhances OR sintering and hinders PMC sintering. The integration of h-BN to the support not only enhances heat transfer in the system but also changes the electrical and chemical environments of the active centers. Zhu et al. [44] indicated that Pt NPs are more negatively charged on vacancy-abundant $\mathrm{BN}$ nanosheets than on $\mathrm{SiO}_{2}$. Liu et al. [49] revealed that Pt NPs stabilized at the grain boundary of BN could be more easily reduced in a propane combustion reaction as compared with those on the surface of $\mathrm{BN}$, and thereby are more active, suggesting different reaction pathways for these catalysts and the possible participation of the grain boundary of the BN support in the reaction. Cao et al. [61] indicated that defects of the Ni/h-BNNS catalyst can strongly influence metal-support interaction due to electron donor/acceptor mechanisms and favor the adsorption and catalytic activation of $\mathrm{CH}_{4}$ and $\mathrm{CO}_{2}$.

As shown in Scheme 1, Pt NP sintering due to OR and PMC mechanisms decelerates under high temperatures in the $\mathrm{Pt} / \gamma-\mathrm{Al}_{2} \mathrm{O}_{3}$-h-BN system. h-BN is an optimal $2 \mathrm{D}$ material for anti-sintering Pt NPs because of its high 
a

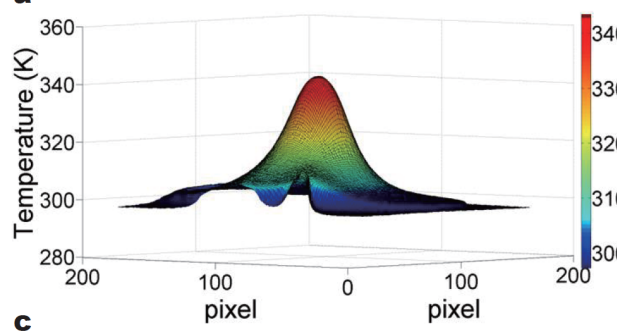

c

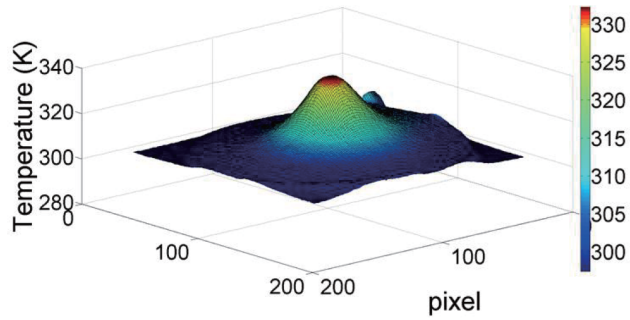

b

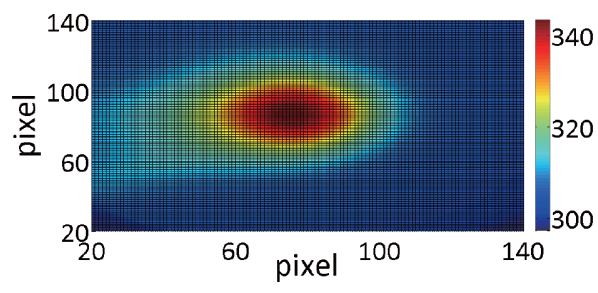

d

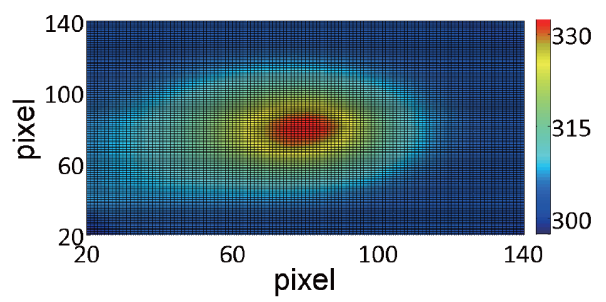

Figure 4 Temperature field distribution of (a, b) $\mathrm{Pt} / \gamma-\mathrm{Al}_{2} \mathrm{O}_{3}$ and (c, d) $\mathrm{Pt} / \gamma-\mathrm{Al}_{2} \mathrm{O}_{3}-\mathrm{h}-\mathrm{BN}$ tested using an infrared thermal imaging camera.

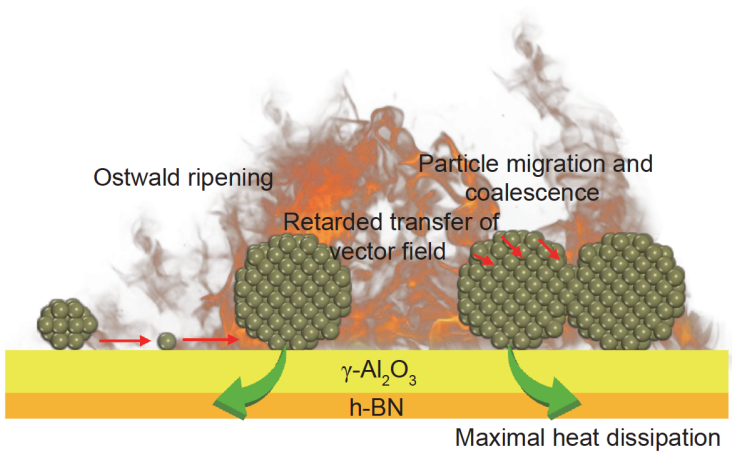

Scheme 1 Schematic of the anti-sintering strategy during the high temperature sintering process.

thermal conductivity. Thermal conductivity is higher and thermal interfacial resistance is lower when $\mathrm{h}-\mathrm{BN}$ is introduced into $\mathrm{Pt} / \gamma-\mathrm{Al}_{2} \mathrm{O}_{3}$, and thereby a large amount of heat can be transported quickly from the surface of $\mathrm{Pt}$ NPs to substrates to inhibit sintering due to PMC and OR mechanisms. The advantage of the present strategy lies in its simplicity and effectiveness as well as in the adaptability to complex environments, such as during realistic chemical reaction conditions. We have extended this to the reducible $\mathrm{Pt} / \mathrm{TiO}_{2}$ system where the introduction of h$\mathrm{BN}$ into $\mathrm{Pt} / \mathrm{TiO}_{2}$ can inhibit Pt NP sintering (Fig. $3 \mathrm{c}$ and Figs S12, S13).

\section{CONCLUSION}

A universal anti-sintering strategy was developed using a combination of theoretical prediction and experimental validation. The ultrahigh anti-sintering performance of $\mathrm{Pt}$
NPs at high temperatures was demonstrated by introducing high-thermal-conductivity h-BN material into $\mathrm{Pt} / \gamma$ $\mathrm{Al}_{2} \mathrm{O}_{3}$ material. This strategy can be extended to other oxide-supported TM NPs. Our work demonstrates a method for controlling the sintering process and provides insight into the development of novel anti-sintering materials and structures.

Received 9 October 2020; accepted 1 January 2021; published online 17 March 2021

1 German RM. Powder Metallurgy and Particulate Materials Processing: The Processes, Materials, Products, Properties, and Applications. Princeton: Metal Powder Industries Federation, 2005

2 Wentorf RH, Devries RC, Bundy FP. Sintered superhard materials. Science, 1980, 208: 873-880

3 Hansen TW, Delariva AT, Challa SR, et al. Sintering of catalytic nanoparticles: Particle migration or Ostwald ripening? Acc Chem Res, 2013, 46: 1720-1730

4 Tauster SJ. Strong metal-support interactions. Acc Chem Res, 1987, 20: 389-394

5 Belton DN, Sun YM, White JM. Metal-support interactions on rhodium and platinum/titanium dioxide model catalysts. J Phys Chem, 1984, 88: 5172-5176

6 Liu K, Zhao X, Ren G, et al. Strong metal-support interaction promoted scalable production of thermally stable single-atom catalysts. Nat Commun, 2020, 11: 1263

7 van Deelen TW, Hernández Mejía C, de Jong KP. Control of metal-support interactions in heterogeneous catalysts to enhance activity and selectivity. Nat Catal, 2019, 2: 955-970

8 Yang Y, Perry IB, Lu G, et al. Copper-catalyzed asymmetric addition of olefin-derived nucleophiles to ketones. Science, 2016, 353: 144-150

9 Qiao B, Wang A, Yang X, et al. Single-atom catalysis of CO oxidation using $\mathrm{Pt}_{1} / \mathrm{FeO}_{x}$. Nat Chem, 2011, 3: 634-641

10 Ouyang R, Liu JX, Li WX. Atomistic theory of Ostwald ripening 
and disintegration of supported metal particles under reaction conditions. J Am Chem Soc, 2013, 135: 1760-1771

$11 \mathrm{Hu}$ SL, Li WX. Metal-support interaction controlled migration and coalescence of supported particles. Sci China Tech Sci, 2019, 62: 762-772

12 Wan Q, Hu S, Dai J, et al. Influence of crystal facet and phase of titanium dioxide on Ostwald ripening of supported Pt nanoparticles from first-principles kinetics. J Phys Chem C, 2019, 123: $11020-11031$

13 Joo SH, Park JY, Tsung CK, et al. Thermally stable Pt/mesoporous silica core-shell nanocatalysts for high-temperature reactions. Nat Mater, 2009, 8: 126-131

14 Lu J, Elam JW, Stair PC. Synthesis and stabilization of supported metal catalysts by atomic layer deposition. Acc Chem Res, 2013, 46: 1806-1815

15 Cargnello M, Delgado Jaén JJ, Hernández Garrido JC, et al. Exceptional activity for methane combustion over modular $\mathrm{Pd@CeO}$ subunits on functionalized $\mathrm{Al}_{2} \mathrm{O}_{3}$. Science, 2012, 337: 713-717

16 Zhang Q, Lee I, Joo JB, et al. Core-shell nanostructured catalysts. Acc Chem Res, 2013, 46: 1816-1824

17 Lee J, Park JC, Song H. A nanoreactor framework of a $\mathrm{Au} @ \mathrm{SiO}_{2}$ yolk/shell structure for catalytic reduction of $p$-nitrophenol. Adv Mater, 2008, 20: 1523-1528

18 Kuo CH, Tang Y, Chou LY, et al. Yolk-shell nanocrystal@ZIF-8 nanostructures for gas-phase heterogeneous catalysis with selectivity control. J Am Chem Soc, 2012, 134: 14345-14348

19 Wu S, Dzubiella J, Kaiser J, et al. Thermosensitive Au-PNIPA yolkshell nanoparticles with tunable selectivity for catalysis. Angew Chem Int Ed, 2012, 51: 2229-2233

20 Rivallan M, Seguin E, Thomas S, et al. Platinum sintering on $\mathrm{H}$ ZSM-5 followed by chemometrics of CO adsorption and 2D pressure-jump IR spectroscopy of adsorbed species. Angew Chem Int Ed, 2010, 49: 785-789

21 Zhao Y, Guo Z, Zhang H, et al. Hydrogenation of diesters on copper catalyst anchored on ordered hierarchical porous silica: Pore size effect. J Catal, 2018, 357: 223-237

22 Das D, Sayari A. Applications of pore-expanded mesoporous silica 6. Novel synthesis of monodispersed supported palladium nanoparticles and their catalytic activity for suzuki reaction. J Catal, 2007, 246: 60-65

23 Hejral U, Müller P, Balmes O, et al. Tracking the shape-dependent sintering of platinum-rhodium model catalysts under operando conditions. Nat Commun, 2016, 7: 10964

$24 \mathrm{Hu}$ KJ, Plant SR, Ellis PR, et al. Atomic resolution observation of a size-dependent change in the ripening modes of mass-selected $\mathrm{Au}$ nanoclusters involved in CO oxidation. J Am Chem Soc, 2015, 137: $15161-15168$

25 Gilroy KD, Elnabawy AO, Yang TH, et al. Thermal stability of metal nanocrystals: An investigation of the surface and bulk reconstructions of Pd concave icosahedra. Nano Lett, 2017, 17: 3655-3661

26 Wang D, Xin HL, Hovden R, et al. Structurally ordered intermetallic platinum-cobalt core-shell nanoparticles with enhanced activity and stability as oxygen reduction electrocatalysts. Nat Mater, 2013, 12: 81-87

27 Han CW, Majumdar P, Marinero EE, et al. Highly stable bimetallic $\mathrm{AuIr} / \mathrm{TiO}_{2}$ catalyst: Physical origins of the intrinsic high stability against sintering. Nano Lett, 2015, 15: 8141-8147

28 Zhao $\mathrm{L}$, Han $\mathrm{T}$, Wang $\mathrm{H}$, et al. Ni-Co alloy catalyst from $\mathrm{LaNi}_{1-x} \mathrm{Co}_{x} \mathrm{O}_{3}$ perovskite supported on zirconia for steam re- forming of ethanol. Appl Catal B-Environ, 2016, 187: 19-29

29 Chaput L, Togo A, Tanaka I, et al. Phonon-phonon interactions in transition metals. Phys Rev B, 2011, 84: 094302

30 Wang K, Glicksman M. Ostwald ripening in materials processing. In: Groza JR, Shackelford JF, Lavernia EJ, et al (Eds.). Materials Processing Handbook. Boca Raton: CRC Press, 2007. 75-94

31 Smoluchowski M. Versuch einer mathematischen theorie der koagulationskinetik kolloider lösungen. Z für Physikalische Chem, 1918, 2: 595

32 Liu Z, Guo Y, Chen Y, et al. The adsorption of $\mathrm{Ru}_{n}(n=1-4)$ on $\gamma$ $\mathrm{Al}_{2} \mathrm{O}_{3}$ surface: A DFT study. Appl Surf Sci, 2018, 440: 586-594

33 Geng X, Yi J. Chapter 6-The development of high-temperature superconductors and 2D iron-based superconductors. In: Hong NH (Ed.). Nano-Sized Multifunctional Materials. Synthesis, Properties and Applications. A Volume in Micro and Nano Technologies. Amsterdam: Elsevier, 2019. 117-144

34 Shinde PV, Singh MK. Fundamentals and Sensing Applications of 2D Materials. Cambridge: Woodhead Publishing, 2019

35 Butler SZ, Hollen SM, Cao L, et al. Progress, challenges, and opportunities in two-dimensional materials beyond graphene. ACS Nano, 2013, 7: 2898-2926

36 Fiori G, Bonaccorso F, Iannaccone G, et al. Electronics based on two-dimensional materials. Nat Nanotech, 2014, 9: 768-779

37 Wang J, Ma F, Liang W, et al. Electrical properties and applications of graphene, hexagonal boron nitride (h-BN), and graphene/h-BN heterostructures. Mater Today Phys, 2017, 2: 6-34

38 Nair RR, Blake P, Grigorenko AN, et al. Fine structure constant defines visual transparency of graphene. Science, 2008, 320: 1308

39 Wang F, Zhang Y, Tian C, et al. Gate-variable optical transitions in graphene. Science, 2008, 320: 206-209

40 Lee C, Wei X, Kysar JW, et al. Measurement of the elastic properties and intrinsic strength of monolayer graphene. Science, 2008 , 321: $385-388$

41 Kakaei K, Esrafili M, Ehsani A. Graphene Surfaces: Particles and Catalysts. London: Academic Press, 2018

42 Wang Y, Mao J, Meng X, et al. Catalysis with two-dimensional materials confining single atoms: Concept, design, and applications. Chem Rev, 2018, 119: 1806-1854

43 Yang XF, Wang A, Qiao B, et al. Single-atom catalysts: A new frontier in heterogeneous catalysis. Acc Chem Res, 2013, 46: 17401748

44 Zhu W, Wu Z, Foo GS, et al. Taming interfacial electronic properties of platinum nanoparticles on vacancy-abundant boron nitride nanosheets for enhanced catalysis. Nat Commun, 2017, 8 : 15291

45 Grammatikopoulos P, Sowwan M, Kioseoglou J. Computational modeling of nanoparticle coalescence. Adv Theor Simul, 2019, 2: 1970019

46 Golberg D, Bando Y, Huang Y, et al. Boron nitride nanotubes and nanosheets. ACS Nano, 2010, 4: 2979-2993

47 Kostoglou N, Polychronopoulou K, Rebholz C. Thermal and chemical stability of hexagonal boron nitride (h-BN) nanoplatelets. Vacuum, 2015, 112: 42-45

48 Liu L, Feng YP, Shen ZX. Structural and electronic properties of $h$ BN. Phys Rev B, 2003, 68: 104102

49 Liu YR, Li X, Liao WM, et al. Highly active Pt/BN catalysts for propane combustion: The roles of support and reactant-induced evolution of active sites. ACS Catal, 2019, 9: 1472-1481

50 Lyalin A, Nakayama A, Uosaki K, et al. Functionalization of monolayer $\mathrm{h}$-BN by a metal support for the oxygen reduction 
reaction. J Phys Chem C, 2013, 117: 21359-21370

51 Preobrajenski $\mathrm{AB}$, Vinogradov $\mathrm{AS}, \mathrm{Ng} \mathrm{ML}$, et al. Influence of chemical interaction at the lattice-mismatched h-BN/Rh(111) and h-BN/Pt(111) interfaces on the overlayer morphology. Phys Rev B, 2007, 75: 254412

52 Peer-Mohammadi H, Rajabpour A, Khanaki M. Grain size facilitating the heat transfer between graphene and silica substrate. Comput Mater Sci, 2018, 149: 348-353

53 Hadjiev VG, Iliev MN, Lv B, et al. Anomalous vibrational properties of cubic boron arsenide. Phys Rev B, 2013, 89: 024308

54 Tan $\mathrm{X}$, Shao $\mathrm{H}, \mathrm{Hu} \mathrm{T}$, et al. High thermoelectric performance in two-dimensional graphyne sheets predicted by first-principles calculations. Phys Chem Chem Phys, 2015, 17: 22872-22881

55 Baraton MI, Merle T, Quintard P, et al. Surface activity of a boron nitride powder: A vibrational study. Langmuir, 1993, 9: 1486-1491

56 Stuart SJ, Tutein AB, Harrison JA. A reactive potential for hydrocarbons with intermolecular interactions. J Chem Phys, 2000, 112: 6472-6486

57 Gottstein G, Shvindlerman LS. Grain Boundary Migration in Metals: Thermodynamics, Kinetics, Applications. Boca Raton: CRC Press, 1999

58 Bai XM, Zhang Y, Tonks MR. Testing thermal gradient driving force for grain boundary migration using molecular dynamics simulations. Acta Mater, 2015, 85: 95-106

59 Desai TG, Millett P, Tonks M, et al. Atomistic simulations of void migration under thermal gradient in $\mathrm{UO}_{2}$. Acta Mater, 2010, 58: 330-339

60 Dong H, Hirvonen $\mathrm{P}$, Fan $\mathrm{Z}$, et al. Heat transport in pristine and polycrystalline single-layer hexagonal boron nitride. Phys Chem Chem Phys, 2018, 20: 24602-24612

61 Cao Y, Maitarad P, Gao M, et al. Defect-induced efficient dry reforming of methane over two-dimensional $\mathrm{Ni} / \mathrm{h}$-boron nitride nanosheet catalysts. Appl Catal B-Environ, 2018, 238: 51-60

Acknowledgements This work was supported by the National Natural Science Foundation of China (21961132026, 51888103, 21878331, 51606192, 91645108 and U1162117), the Nanotechnology Specific Project of the National Key Research and Development Program (2020YFA0210900), the CAS Pioneer Hundred Talents Program, and the Science Foundation of China University of Petroleum, Beijing (C201604).

Author contributions Jiang G, Zhang $\mathrm{H}$ and Liu JX conceived and designed the experiments and modeling; Wang S, Li Z, Li Y, Li R, Jiang $\mathrm{Y}$ and $\mathrm{Li} \mathrm{T}$ performed the experiments and analyzed the data; Wang $\mathrm{S}$, Yang $\mathrm{M}$ conducted the molecular dynamics simulation and density functional theory calculations; Yu C, Wang Y, Zhao Z and Xu C participated in the discussion of the results and the preparation of the paper. The manuscript was written through contributions of all authors. All authors have given approval to the final version of the manuscript.

Conflict of interest The authors declare that they have no conflict of interest.

Supplementary information Experimental and theoretical details and supporting data are available in the online version of the paper.

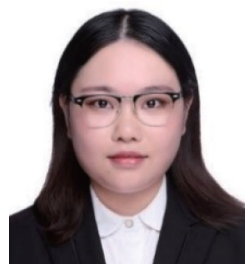

Shuting Wang received her BE degree from China University of Petroleum, Beijing in 2015 and is now a $\mathrm{PhD}$ candidate under the supervision of Prof. Guiyuan Jiang at China University of Petroleum, Beijing. Her current research interests include molecular dynamics and thermal arrangement on catalysts.

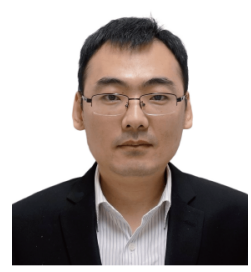

Jin-Xun Liu is currently working as a research fellow at the School of Chemistry and Materials Science, University of Science and Technology of China (USTC). He completed his $\mathrm{PhD}$ degree from Dalian Institute of Chemical Physics (DICP) and was a postdoctoral fellow at the Department of Chemical Engineering and Chemistry, Eindhoven University of Technology (TU/e) and at the Department of Chemical Engineering, University of Michigan-Ann Arbor (UMich). His research expertise spans computational heterogeneous catalysis, electrocatalysis, machine learning, and molecular simulation.

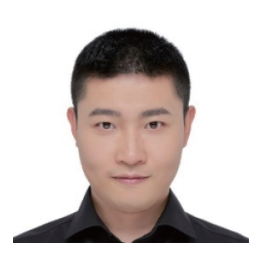

Hang Zhang earned his BSc degree in physics from Nanjing University in 2007, and received his $\mathrm{PhD}$ degree in physics from the University of California, Riverside, in 2012. Then he started his postdoctoral research work at California Institute of Technology. In 2016, he joined the Institute of Engineering Thermophysics, Chinese Academy of Sciences as a professor. His research interests are on heat transport in nano-/micro-scale and energy functional materials and devices.

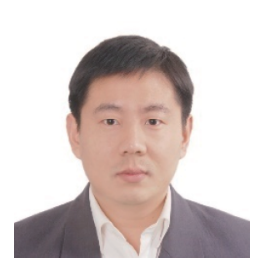

Guiyuan Jiang received his BSc and MSc degrees from China University of Petroleum, Beijing under the supervision of Prof. Chunming $\mathrm{Xu}$, and $\mathrm{PhD}$ degree from the Institute of Chemistry, Chinese Academy of Sciences with Prof. Yanlin Song. He is currently a professor at the University of Petroleum, Beijing. He was a visiting postdoctor at the University of California, Riverside in 2010 with Professor Pingyun Feng, and visiting scholar in Prof. Yadong Li's group at Tsinghua University in 2013-2014. His research interests mainly focus on catalytic conversion of light hydrocarbons and process intensification.

\section{基于热管理策略实现负载型铂纳米颗粒的抗烧结}

王淑婷 ${ }^{1}$, 李子安 ${ }^{2,4}$, 杨明 ${ }^{3,4}$, 李宇明 ${ }^{1}$, 李然家 ${ }^{1}$, 余长春 ${ }^{1}$, 王雅君 ${ }^{1}$, 姜尧 ${ }^{1}$, 李涛 ${ }^{3,4}$, 刘进勋 ${ }^{5^{*}}$, 张航 ${ }^{3,4^{*}}$, 赵震 ${ }^{1}$, 徐春明 ${ }^{1}$,

摘要 抑制催化剂在高温条件下的烧结仍是目前多相催化领域的 一个巨大挑战. 本文报道了高热导率六方氮化硼可作为 $\gamma-\mathrm{Al}_{2} \mathrm{O}_{3}$ 负 载型铂纳米粒子优异的抗烧结材料. 在升温条件下, 六方氮化硼的 高热导率能够确保铂纳米粒子到 $\gamma-\mathrm{Al}_{2} \mathrm{O}_{3}$ 的有效散热, 从而实现铂 纳米粒子Ostwald熟化烧结和颗粒碰撞烧结均被抑制. $\mathrm{TiO}_{2}$ 负载的 铂纳米粒子在引入六方氮化硼后, 铂纳米粒子的烧结同样被抑制. 本工作提出了一种基于热管理实现抗烧结的通用策略, 为在多相 催化中广泛应用的抗烧结材料和其结构设计提供了新的思路. 